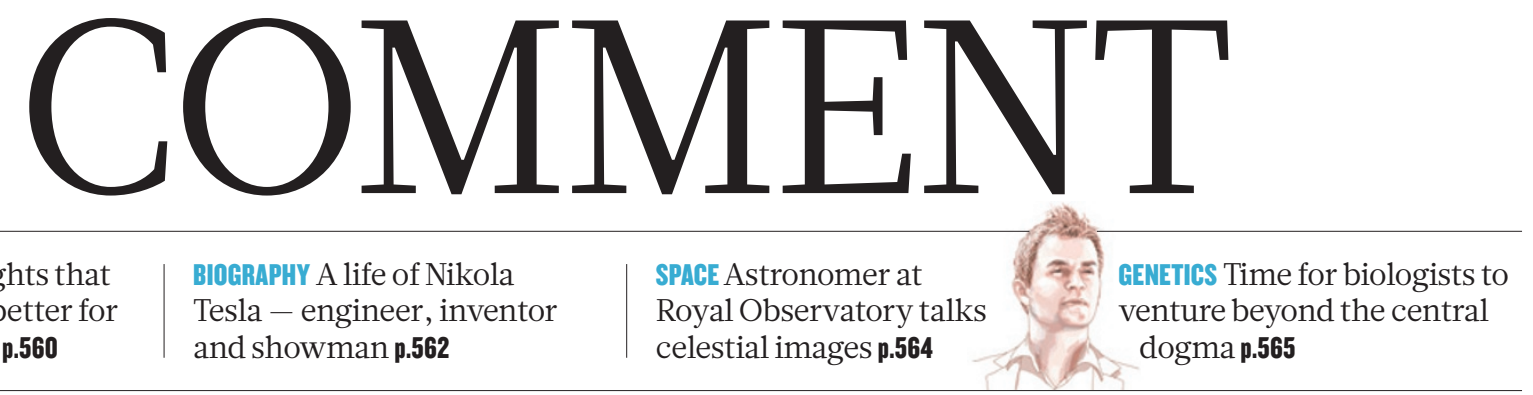

ENVIRONMENT Street lights that use less energy are better for people and animals $\mathbf{p . 5 6 0}$ and showman $\mathbf{p . 5 6 2}$
Royal Observatory talks celestial images p.564 dogma .565

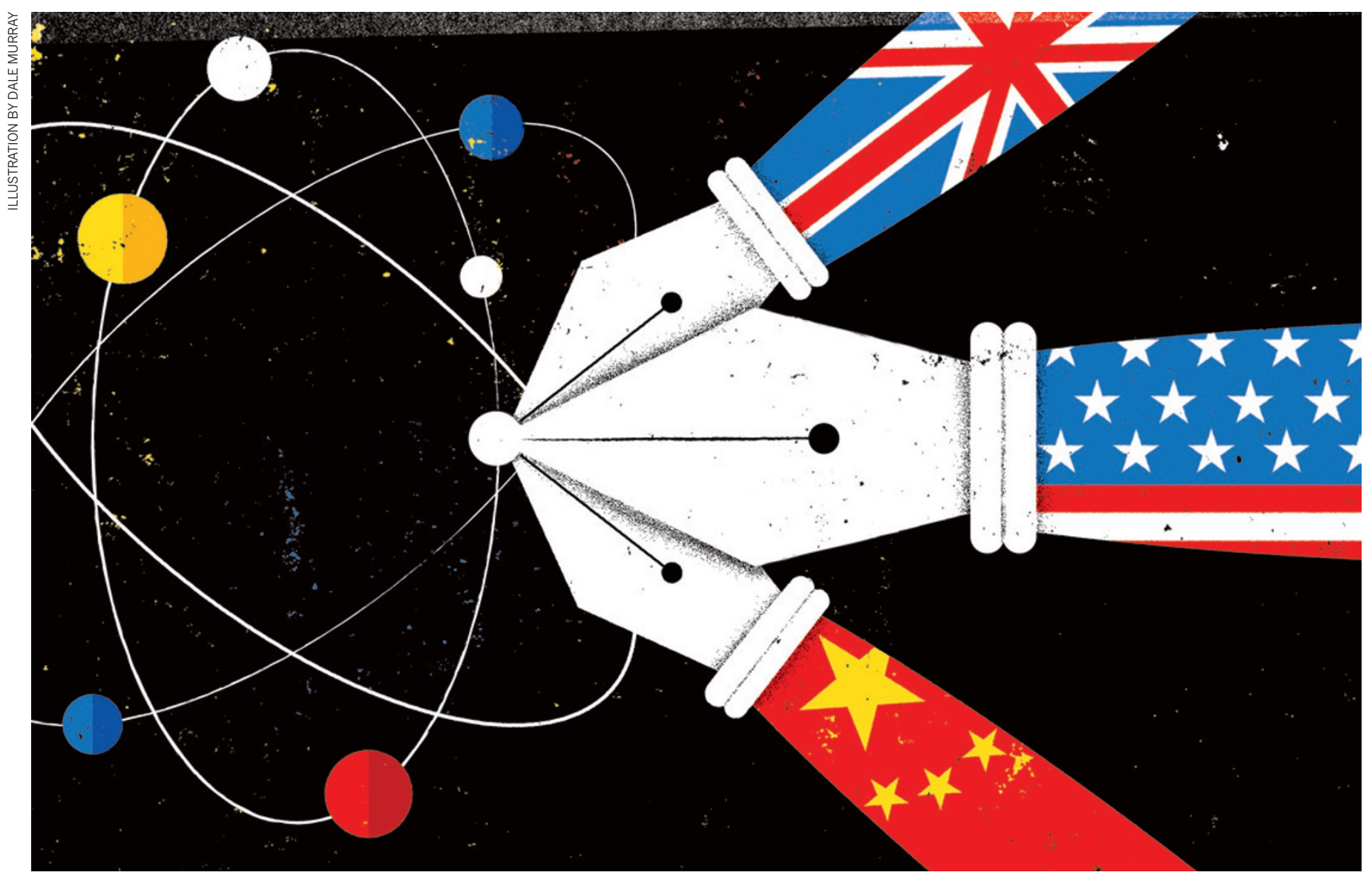

\title{
The fourth age of research
}

\author{
Jonathan Adams analyses papers from the past three decades and finds that \\ the best science comes from international collaboration.
}

$\mathrm{R}$ esearch has progressed through three ages: the individual, the institutional and the national. Nations competed to be at the cutting edge because this contributed to the wider economy through knowledge, new processes and products.

Today, we are entering a fourth age of research, driven by international collaborations between elite research groups. This will challenge the ability of nations to conserve their scientific wealth either as intellectual property or as research talent ${ }^{1-3}$. Tensions are growing: between the knowledge a country needs to remain competitive and the assets it can exclusively secure, and between the collaborative and domestic parts of the research base. Institutions that do not form international collaborations risk progressive disenfranchisement, and countries that do not nurture their talent will lose out entirely.

To explore the scale of this challenge, I analysed data on research articles and reviews from Thomson Reuters Web of Science between 1981 and 2012. I included papers in a country's tally if one or more author addresses included that country, but no weighting was applied for the number of authors or addresses on each paper. For the 25 million papers I included in my analysis, I calculated the balance of international and domestic research collaboration for established economies (the United States, the United Kingdom, Germany, France, the Netherlands, Switzerland) and emerging ones (China, India, South Korea, Brazil, Poland). I looked particularly at all $>$ 


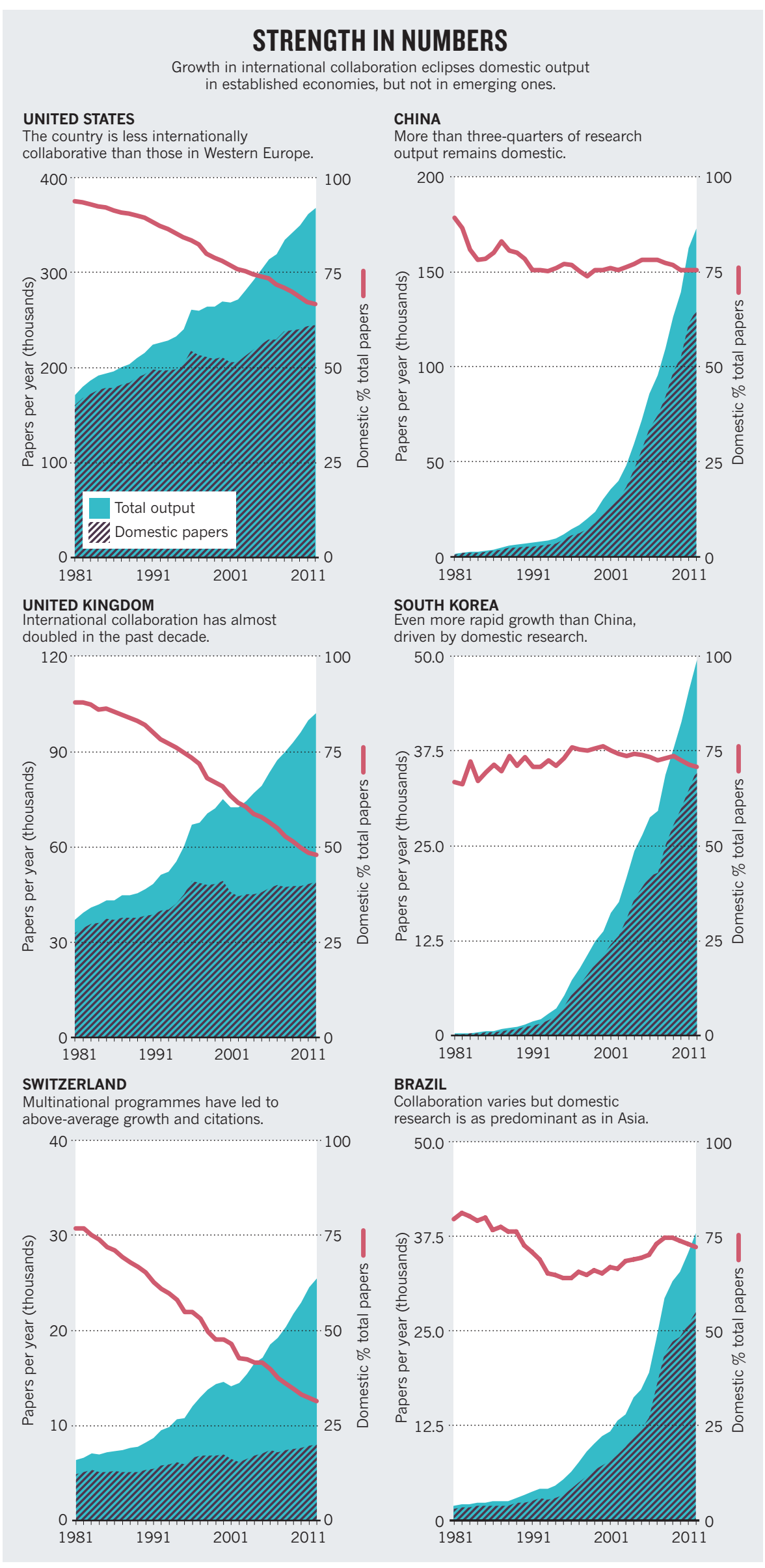

papers from the United Kingdom and the United States that listed multiple authors. 屵 Then I probed the relative citation impact of domestic and international research in the two countries.

I found that, over more than three decades, domestic output - papers that list only authors from the home country - has flatlined in the United States and in Western European countries. The rise in total annual output for each country is due to international collaboration. As a result, the percentage of papers that are entirely 'home grown' is falling. In emerging economies, by contrast, domestic output is rapidly expanding (see 'Strength in numbers').

These shifts stand to change the dynamics of how nations invest in science, who owns its outputs and who best exploits them.

\section{BORDER CROSSING}

In Western Europe in 1981, domestic share of output was about five papers in every six published by each country, but fell to half of total output in 2011. The United States started as less collaborative - just $6 \%$ of US papers in 1981 had a foreign co-author, but it too has had a marked fall in domestic share of output: it is the most frequent partner for many other nations. Nonetheless, it remains less internationally collaborative than Western Europe.

In emerging economies in 1981, the domestic share of output was similar to that of the established economies. Today, about 75\% of the research output of China, Brazil, India and South Korea remains entirely domestic. The total volume of papers from these four countries has increased 20 -fold - from fewer than 15,000 papers annually in 1981 to more than 300,000 papers now. Despite its European location, Poland's balance of domestic and collaborative papers is closer to this group (see Supplementary Information at go.nature. com/nszeck). Quantity is now being matched by significant improvements in quality: the citation impact of more than $10 \%$ of China's domestic research is already above twice the world average.

For established economies, total national research output has more than doubled over the past 30 years. Meanwhile, domestic output has increased by only about $50 \%$ for all except the Netherlands (which more than doubled). After the mid-1990s, the domestic research output of the United Kingdom (47,500 papers per year), Germany $(45,000$ papers) and France (30,000 papers) levelled off while international collaboration in these countries increased more than ten-fold.

What fuelled this growth in collaboration? Much of it has come from bilateral partnerships rather than multinational programmes (see Supplementary Information). For instance, less than $1 \%$ of UK papers from 2003 to 2012 list co-authors from all three of France, Germany and the United States, and 
u less than $0.1 \%$ of US output over the same period has co-authors from the United Kingdom, Germany and China together.

Switzerland is an interesting outlier. For a small country, its research output has seen above-average growth and a high average citation impact. Today, more than two-thirds of its publications have a foreign co-author. A large part of this comes from the country's hosting of multinational programmes, such as CERN (Europe's particle-physics lab) and the World Health Organization, both in Geneva.

Citation impact is typically greater when research groups collaborate, and the benefit strengthens when co-authorship is international $^{4-6}$. I calculated the citation impact of each UK and US paper published in 2001 and then for 2011 by normalizing citation count to take into account the time elapsed since year of publication and the subject area of the journal. For each of these years, I then calculated an average normalized citation impact (where 1.0 is the world average) for papers that were purely domestic and for papers with a foreign co-author.

For both countries, papers that are internationally collaborative are cited relatively more often than purely domestic papers. And this 'impact premium' rose in both countries by around 20\% between 2001 and 2011 (see 'Impact premium').

\section{A CASE IN POINT}

A closer look at the United Kingdom reveals the drivers of some of these changes. The UK government's Department for Business, Innovation \& Skills (BIS) reports both rising volume and rising average citation impact for the UK research base relative to the world average. My analysis shows that this impact (up from 1.21 in 2001 to 1.47 by 2011) is mainly attributable to the near-doubling of its international collaboration (from 26,608 to 50,423 papers with an average impact up from 1.48 to 1.72). By comparison, the UK domestic research base, which BIS has never analysed separately, has changed much less in quantity and quality. In 2001, the country published 46,671 domestic papers with an average impact of 1.05; in 2011 it published 47,323 domestic papers with an average impact of 1.21. And in 2010, the number of UK papers with no overseas co-author actually fell below the count of internationally collaborative papers.

The benefits of collaboration are systematic. I found that $130 \mathrm{UK}$ universities and colleges published more than 100 research articles and reviews in journals indexed on Thomson Reuters Web of Science in 2002-11. Around half of these universities have an international co-author on less than $40 \%$ of their papers. Average impact in this group rarely gets much above 1.1. By contrast, research staff in institutions with greater than $50 \%$ international

\section{IMPACT PREMIUM}

In the United States (US) and the United Kingdom (UK), papers with at least one author from another country are cited more often than purely domestic work.

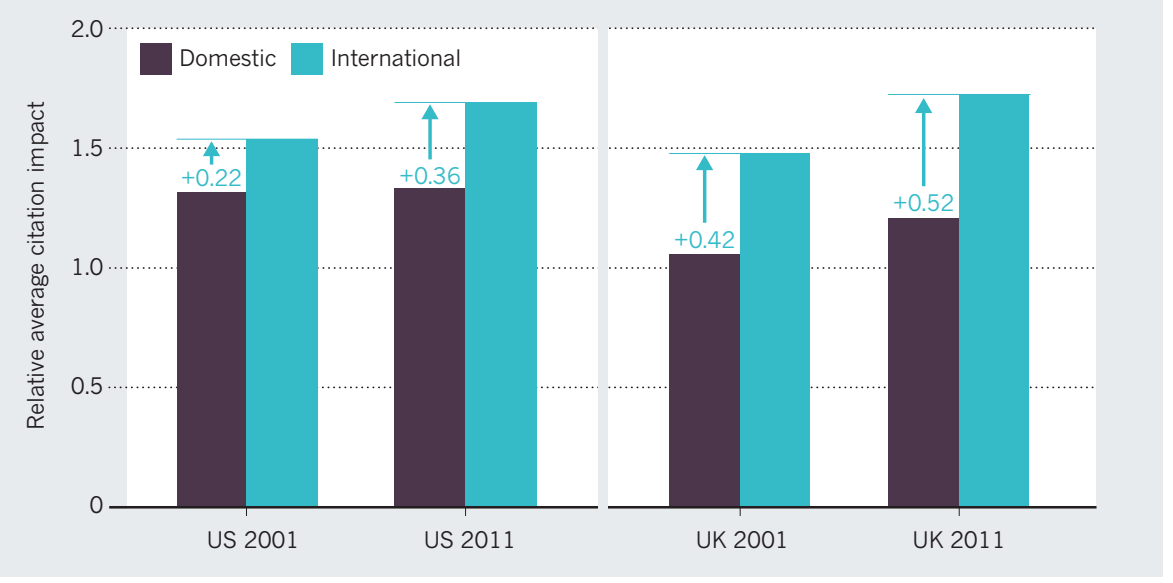

co-authorship on their papers had an average citation impact above 1.6 (see Supplementary Information). This category includes the five or six UK universities that are generally recognized as standing ahead of others, including the universities of Oxford and Cambridge.

This same handful of elite institutions receives about one-third of all available core research income from the UK highereducation funding "Elitenational councils, more than universities one-third of the total are also leading international collaborators." available research grant and contract income and one-third of all research-council studentships. By contrast, the 65 or so UK universities that have an international co-author on less than $40 \%$ of their papers collectively account for less than $10 \%$ of funding-council research money, less than $5 \%$ of research grants and contracts and less than $1 \%$ of research-council studentships (my analysis; using data from the UK Higher Education Statistics Agency).

\section{CONTEMPORARY GIANTS}

First-rate researchers are, and always were, thinly distributed. In the past they could collaborate only intermittently. Contemporary giants call more readily across the desolate intervals of space (to paraphrase Friedrich Nietzsche) and rapidly receive answers, because information technology has sharply reduced the costs of collaboration ${ }^{7}$.

Excellence seeks excellence, so elite national universities are also leading international collaborators. Exceptional research groups share ideas, resources and outcomes. For example, the most frequent international partners of the University of Cambridge, UK, are the Max Planck institutes in Germany, the Massachusetts Institute of Technology and Harvard University, both in Cambridge; the
California Institute of Technology in Pasadena; the University of California, Berkeley; and the universities of Toronto, Heidelberg and Tokyo. Harvard's frequent international partners are Imperial College London, University College London, the Max Planck institutes, the Karolinska Institute in Stockholm and the universities of Cambridge, Toronto and Geneva. Internationally co-authored papers are more highly cited because the authors are more likely to be doing excellent research. Multinational programmes are still marginal as drivers of performance.

So, in this fourth age of research there is a growing divide between international and domestic research. This will influence each nation's ability to draw on the global knowledge base, and could in turn compromise national scientific wealth. For established economies, the risks are a gradual financial and intellectual separation between institutions that are largely international and those that are largely national. Such separation could lead to the erosion of adequate regional competency for future research training and collaboration and for knowledge flow to the national industrial base.

Government policy should focus on three issues to address these risks. First, in this age of big data that are internationally shared, the question will be who has the skills to exploit knowledge assets fastest, not who owns them. Shared knowledge and discovery sideline the idea of securing intellectual property by commercial confidentiality and patenting. The growing scarcity of truly able researchers could lead to a 'global war for talent ${ }^{8}$. So governments must provide and sustain conditions that attract and support the best scientists, otherwise talent flows elsewhere and there is no capacity to generate replacements.

Second, incentives must be put in place to enable universities to participate in international networks. For example, tangible projects involving participation could be 
given explicit recognition and credit in systems for assessing research quality (such as the UK Research Excellence Framework). Insight into the evolving research of the emerging economies will be limited without active engagement and collaboration. Relying simply on what is published in journal articles has long been recognized as a poor mode of knowledge transfer ${ }^{9}$.

Third, collaboration must include European and US researchers in Asian and South American laboratories. The older economies can no longer rely on the best foreign researchers to come and visit. Maintaining a talent pool is necessary, but it is not sufficient: if a nation really wants to remain at the highest level scientifically, it needs to get its talent out and about - and then bring it back again. One way of doing this is to create worthwhile travel and exchange programmes that include an assured post for the returning researcher. The United Kingdom has a shocking record on mobility in European research programmes and the United States has the lowest level of international collaboration among the G7 countries. By contrast, the Netherlands achieves excellence by enabling its researchers to be much more mobile, despite its lesser resources ${ }^{10}$.

Impact and innovation will flow from a coalition of the willing, not the straitjacket of international policy and coordination. Multinational programmes are not the answer, nor are academic memoranda of understanding. To maintain the dividend that governments garner from research excellence, they must ensure that universities and their researchers have the resources, facilities and incentives to create and sustain flourishing partnerships. .

Jonathan Adams was formerly director of research evaluation at Thomson Reuters and is now a researchmanagement consultant in Leeds, UK. e-mail:jonathanzadams@gmail.com

1. May, R. M. Science 275, 793-796 (1997)

2. Adams, J. Nature 396, 615-618 (1998).

3. Adams, J. Nature 490, 335-336 (2012)

4. Van Raan, A. F. J. Scientometrics 42, 423-428 (1998).

5. Adams, J., Gurney, K. A. \& Marshall, S. Scientometrics 72, 325-344 (2007).

6. Schmoch, U. \& Schubert, T. Scientometrics 74, 361-377 (2008)

7. Adams, J. D., Black, G. C., Clemmons, J. R. \& Stephan, P. E. Res. Pol. 34, 259-285 (2005)

8. Dobbs, R., Lund, S. \& Madgavkar, A. 'Talent tensions ahead: a CEO briefing.' McKinsey Quarterly (November 2012); available at http://go.nature.com/hz7ars.

9. Gibbons, M. et al. The New Production of Knowledge (Sage, 1994).

10.Gurney, K. \& Adams, J. Tracking UK and International Researchers by an Analysis of Publication Data (Higher Education Policy Institute, 2005).

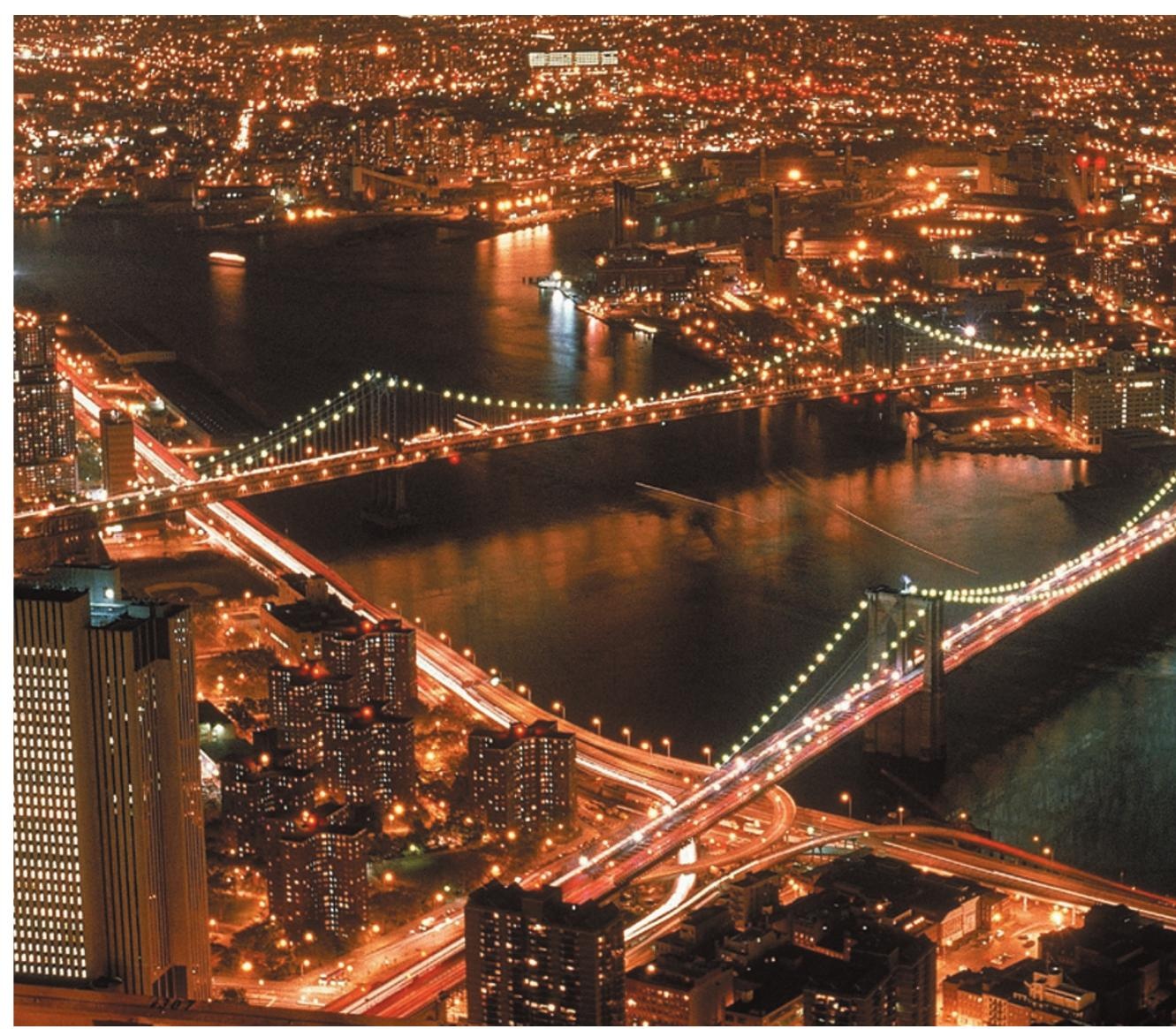

Wasted light from street lights, such as those in New York City, contributes to skyglow.

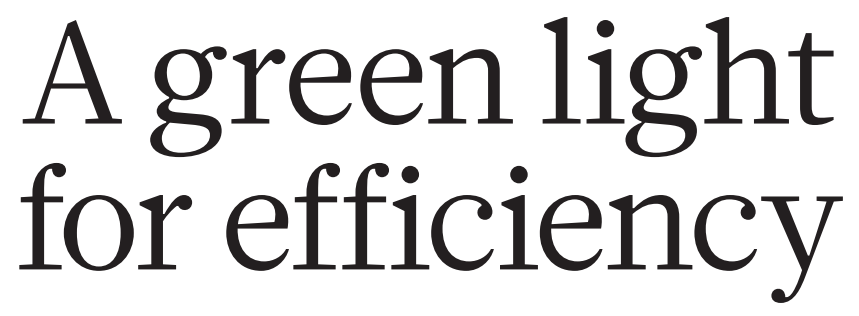

Efforts to improve street lights are providing a rare opportunity to cut both financial and environmental costs, argues Kevin Gaston.

$\mathrm{O}$ ver the past few years, local governments in towns and cities across the world have been dimming street lights, turning them off for parts of the night, investing in more energy-efficient technologies and gradually modernizing old lighting systems. Hard times and tight budgets have helped to drive this flurry of activity.

The combination of financial pressures, a broad array of new lighting technologies and a richer understanding of the importance of natural-light cycles to the health of many organisms presents an unusual opportunity. To take advantage, environmental scientists must work quickly to gather and build on existing knowledge about the effects of artificial light on plants and animals, and must collaborate with those responsible for the development and implementation of public lighting schemes.

As well as disrupting the development, physiology and behaviour of many organisms, grid-based electric lighting is estimated to produce 1.5 billion tonnes of carbon dioxide each year globally. Moreover, artificial light disturbs people's natural circadian rhythms. Various studies have linked this disturbance to conditions such as breast cancer ${ }^{1}$ and obesity. A notorious impediment to astronomical observations, artificial light also robs us of moonlit landscapes and properly dark or star-filled skies.

Most existing street-lighting systems are inefficient and expensive. Much of the light they produce is wasted, contributing to skyglow often tens and possibly hundreds of 